\title{
The prognostic significance of loss of the androgen receptor and neuroendocrine differentiation in prostate biopsy specimens among castration-resistant prostate cancer patients
}

\author{
AKIRA KOMIYA $^{1}$, KENJI YASUDA ${ }^{1}$, AKIHIKO WATANABE ${ }^{1}$, \\ YASUYOSHI FUJIUCHI ${ }^{1}$, TOYONORI TSUZUKI ${ }^{2}$ and HIDEKI FUSE ${ }^{1}$ \\ ${ }^{1}$ Department of Urology, Graduate School of Medicine and Pharmaceutical Sciences for Research, \\ University of Toyama, Toyama 930-0194; ${ }^{2}$ Department of Pathology, \\ Nagoya Daini Red Cross Hospital, Nagoya 466-8650, Japan
}

Received October 9, 2012; Accepted December 21, 2012

DOI: $10.3892 / \mathrm{mco} .2013 .69$

\begin{abstract}
Prostate cancer (PCa) is a leading cause of mortality, and despite good response to androgen ablation this response is eventually lost. In the present study, androgen receptor (AR) expression and neuroendocrine differentiation (NED) were evaluated in hormone-sensitive (HSPC) and castration-resistant prostate cancers (CRPC). Prostate tissues were obtained from $20 \mathrm{HSPC}$ patients at diagnosis and 28 CRPC patients at castration-resistant progression. AR, chromogranin A (CGA) and neuron-specific enolase (NSE) were evaluated by immunohistochemical staining (IHS) in representative positive cores for PCa. IHS intensity was graded as negative, 0 ; positive, $1+$ and strongly positive, $2+$. The proportion of the $1+$ and $2+$ areas in PCa cells was determined. PCa was considered to be in NED if $\geq 50 \%$ of the tumor cells were $1+$ or $2+$ for CGA or NSE. The observed IHS intensity $(0 / 1+/ 2+)$ for AR, CGA and NSE was 0/4/16, 5/11/4 and 11/4/5 in HSPC patients and 9/3/16, 5/8/15 and 8/4/16 in CRPC patients, respectively. AR expression was positive in all the HSPC and 19/28 CRPC patients $(\mathrm{P}=0.0049)$. NED was observed in 9/20 HSPC and 20/28 CRPC patients $(\mathrm{P}=0.0649)$. NED was significantly associated with a negative AR expression in CRPC patients $(\mathrm{P}=0.0292)$. Multivariate analysis revealed that age, AR expression and strong NED were independent parameters for prognosis following castrationresistant progression. In conclusion, prostate biopsy following castration-resistant progression was necessary. AR was lost in a subset of CRPC. NED was observed more frequently in CRPC vs. HSPC and was associated with a worse prognosis.
\end{abstract}

Correspondence to: Dr Akira Komiya, Department of Urology, Graduate School of Medicine and Pharmaceutical Sciences for Research, University of Toyama, 2630 Sugitani, Toyama 930-0194, Japan

E-mail: komiya@med.u-toyama.ac.jp

Key words: androgen deprivation therapy, castration-resistant prostate cancer, neuroendocrine differentiation, prostate cancer

\section{Introduction}

Prostate cancer $(\mathrm{PCa})$ is a leading cause of mortality in Western countries. In Japan, PCa incidence and mortality rates are on the increase, despite efforts to screen and diagnose patients early and despite extensive efforts to treat this disease $(1,2)$. There are a number of modalities for localized PCa. However, androgen deprivation therapy remains the standard method used to treat patients with advanced PCa. During hormone therapy, PCa responds well to androgen ablation initially. However, this response is gradually lost and the disease becomes castration-resistant prostate cancer (CRPC), defined as disease progression, even in the presence of castration levels of circulating androgens $(3,4)$. The androgen receptor (AR) remains functional and is important in the mechanisms of CRPC (5), even at this stage.

Evidence for persistent hormone dependence in CRPC facilitated the development of novel anti-androgens capable of blocking testosterone synthesis by the testes as well as adrenal glands and prostate tumor tissue. Abiraterone acetate is an oral, selective and irreversible inhibitor of CYP17, a critical enzyme in androgen biosynthesis, which blocks non-gonadal androgen production. Abiraterone at a dose of $1000 \mathrm{mg} /$ day in combination with prednisone at a dose of $10 \mathrm{mg} / \mathrm{day}$ was approved by the Food and Drug Administration (FDA) in April, 2011, and by the European Medicines Agency (EMA) in July, 2011 for the treatment of metastatic CRPC. The approvals were based on the results of the COU-AA-301 trial conducted in patients who received previous docetaxel chemotherapy, which demonstrated a survival benefit for the experimental arm versus the placebo (6). New anti-androgens with improved binding properties have also been developed. One of these agents is enzalutamide, an oral AR antagonist small molecule that binds to ARs with a higher affinity compared to bicalutamide and blocks AR nuclear translocation, co-activator recruitment and DNA binding without agonist activity when AR is overexpressed (7). Results of the AFFIRM trial showed that enzalutamide was approved by the FDA in August, 2012 (8). These novel compounds were reported to have survival benefits. However, the CRPC 
is likely to eventually progress to a phase of disease that is resistant to these types of therapy.

One of the mechanisms of androgen-independent (AI) progression of $\mathrm{PCa}$ is neuroendocrine differentiation (NED). Neuroendocrine (NE) cells originally exist in the normal prostate acini and duct and they regulate prostatic growth, differentiation and secretion. The lack of AR expression is indicative of the AI activity of NE cells. Clusters of malignant $\mathrm{NE}$ cells are found among adenocarcinoma cells in most PC, sharing a common clonal origin. The prostate NE cells affect the target cells in an AI manner. Therefore, the NE pathway is thought to be one of the most significant mechanisms for AIPC or CRPC (9). NE cells are detected by immunohistochemical staining (IHS) using antibodies against neuropeptides, of which CGA and NSE are the most thoroughly investigated and are believed to be the best markers for prostatic NED (9). Using CGA and NSE as NE markers, Tanaka et al (10) reported that lesions predominantly composed of a neuroendocrine cell tumor were found in 4 of 20 autopsy cases (Japanese patients with PCa). However, AR is expressed in almost all types of cancer of the prostate, before and after androgen ablation therapy (11). Specific downregulation of the AR with anti-AR antibodies or siRNAs results in AI prostate cancer (or CRPC), cell growth inhibition and a reduction in PSA expression $(12,13)$. In addition, recent clinical data, such as abiraterone acetate and enzalutamide, support the AR function in CRPC.

The aims of this study were to compare the AR expression and NED between hormone-sensitive PCa (HSPC) and CRPC patients using IHS and to analyze the diagnostic and prognostic significance of this expression in CRPC.

\section{Materials and methods}

Patients and PCa tissues. PCa tissues were retrospectively obtained using prostate needle biopsies from 20 HSPC patients at initial diagnosis. Consecutive CRPC specimens were obtained using prostate needle biopsies in 24 patients and transurethral resections (TUR) in 4 patients (CRPC biopsy). Cores ( $\geq 10)$ were obtained using Transrectal Ultrasound-Guided Prostate (TRUS) biopsies. CRPC was defined as three increases in the PSA level at least 1 month apart, or evidence of a new clinical disease while the patient was receiving androgen deprivation therapy and the testosterone levels were at castrate levels (14). Patient characteristics are shown in Table I. The median follow-up following CRPC biopsies was 15.6 months (range, 1-57). From the formalin-fixed paraffin-embedded tissue samples, multiple $4-\mu \mathrm{m}$ sections were prepared using a microtome and transferred to glass slides (Fisherbrand Superfrost Plus; Fisher Scientific, Pittsburg, PA, USA). Chromogranin A (CGA), neuron-specific enolase (NSE) and AR were immunohistochemically stained in the representative positive cores or TUR specimens for PCa.

Antibodies. Antibodies for the IHS were: Anti-CGA, a rabbit polyclonal antibody (A0430; dilution, 1:800) (Dako, Carpinteria, CA, USA); anti-NSE antibody, a mouse monoclonal antibody (M0873; dilution, 1:200) (Dako) and anti-AR antibody, a mouse monoclonal antibody (BSB6076; dilution, 1:50) (BioSB).

IHS. The glass slides were incubated with the primary antibodies at an optimized titer and were diluted using Universal Blocking
Table I. Patient characteristics.

\begin{tabular}{lcrrrr}
\hline & \multicolumn{2}{c}{ HSPC } & & \multicolumn{2}{c}{ CRPC } \\
\cline { 2 - 3 } \cline { 5 - 6 } Variables & Mean & SD & & Mean & SD \\
\hline Age (years) & 74.1 & 6.2 & 73.3 & 7.1 \\
iPSA (ng/ml) & 1110 & 2141.3 & 412.4 & 750.3 \\
rPSA (ng/ml) & 77.3 & 175.0 & & \\
Gleason score & 7.9 & 1.5 & & \\
Time to CRPC & n.a. & & 33.5 & 51 \\
(months) & & & & \\
No. & & & & \\
M+ & 10 & & 3 & \\
M- & 10 & & 3 & \\
\hline
\end{tabular}

HSPC, hormone-sensitive prostate cancer; CRPC, castration-resistant prostate cancer; SD, standard deviation; iPSA, initial prostate-specific antigen; rPSA, PSA at castration-resistant progression; M, metastasis; n.a., not available.

Reagent (BioGenex, Fremont, CA, USA) for $30 \mathrm{~min}$, then washed three times with KN buffer (KN-09001; Pathology Institute, Toyama, Japan). The sections were then incubated with a horseradish peroxidase dextran polymer-labeled goat anti-mouse antibody or goat anti-rabbit antibody (ChemMate EnVision kit; dilution 1:100) (Dako) for $30 \mathrm{~min}$ at room temperature (RT). The sections were then washed three times in KN buffer and incubated at RT with 3,3'-diaminobenzidine (DAB; Dako) for 10 $\min$. The sections were rinsed several times with distilled water and were counterstained with Mayer's hematoxylin, dehydrated, cleared and mounted with resinous mounting medium (15).

The staining intensity was graded as negative, 0 ; positive, $1+$ and strongly positive, $2+$ (Fig. 1). The proportion of $1+$ and $2+$ areas in the PCa cells was determined. These analyses were carried out by an experienced pathologist (T.T.). PCa was regarded as NED if $\geq 50 \%$ of the tumor cells were positive for CGA and/or NSE. In addition, PCa was regarded as strong NED if $\geq 50 \%$ of the tumor cells were $2+$ for CGA and/or NSE.

Statistical analysis. Statistical analysis was performed using the Chi-square test to compare the two groups. The cause-specific survival was estimated for each study group using the Kaplan-Meier method and the differences were assessed using the Wilcoxon test. For the multivariate analysis, the Cox proportional hazard model was used to identify independent variables to predict cause-specific survival following CRPC biopsy. $\mathrm{P}<0.05$ was considered to indicate a statistically significanct difference. We used the JMP software version 8.0.1 (SAS Institute, Tokyo, Japan) for the statistical analyses. The study was approved by the institutional review board of the University of Toyama.

\section{Results}

Immunohistological staining intensity. Distribution of the staining intensity is shown in Table II. CRPC exhibited more 
Table II. Distribution of IHS intensity.

\begin{tabular}{|c|c|c|c|c|c|c|}
\hline \multirow[b]{2}{*}{ IHS intensity } & \multicolumn{3}{|c|}{ HSPC } & \multicolumn{3}{|c|}{ CRPC } \\
\hline & CGA (No.) & NSE (No.) & AR (No.) & CGA (No.) & NSE (No.) & AR (No.) \\
\hline 0 & 5 & 11 & 0 & 5 & 8 & 9 \\
\hline $1+$ & 11 & 4 & 4 & 8 & 4 & 3 \\
\hline $2+$ & 4 & 5 & 16 & 15 & 16 & 16 \\
\hline
\end{tabular}

IHS, immunohistochemical staining; 0, negative; 1+, positive; 2+, strongly positive; HSPC, hormone-sensitive prostate cancer; CRPC, castration-resistant prostate cancer; CGA, chromogranin A; NSE, neuron-specific enolase; AR, androgen receptor.

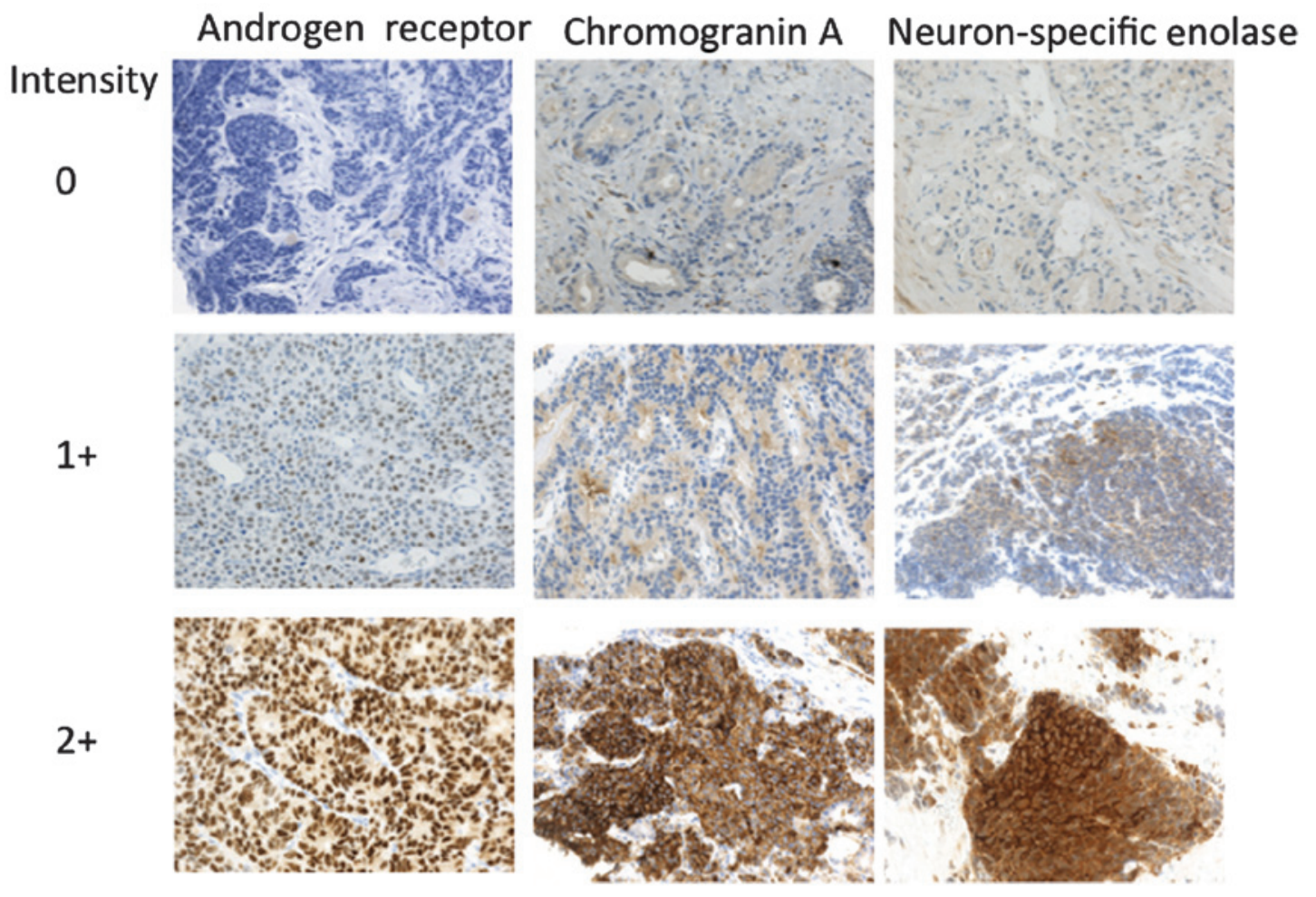

Figure 1. Immunohistochemical staining intensity: 0, negative; $1+$, positive and 2+, strongly positive.

cases with strong NE intensity. The AR expression was positive in all the HSPC. However, 9/28 (32.1\%) CRPC patients were negative for $\mathrm{AR}$, which was more frequent compared to HSPC patients $(\mathrm{P}=0.0049$, Table III). NED was positive in $9 / 20$ HSPC (45.0\%) and in 20/28 CRPC (71.4\%). CRPC showed a tendency to have more NED compared to HSPC ( $\mathrm{P}=0.0649$; Table III).

In CRPC, $11 / 19$ patients $(57.9 \%)$ were NED-positive when the AR was positive. However, NED was positive in the CRPC with a negative AR expression $(n=9)$. Therefore, NED was significantly associated with a negative AR expression in CRPC ( $\mathrm{P}=0.0292$, Table IV).

Survival after CRPC biopsy. Table V shows the treatment modalities in CRPC patients before and after CRPC biopsy. Prior to CRPC biopsy, the main treatments were hormonal manipulations, whereas cytotoxic agents were mainly used following CRPC biopsy (Table V).
The cause-specific survival was available in 27 patients with CRPC. Fig. 2 shows survival curves based on the AR expression in CRPC. Nine CRPC patients were negative for the AR at CRPC biopsy. AR expression was not associated with prostate cancer-specific survival in this univariate analysis. By contrast, strong NED was associated with a poorer prognosis following CRPC biopsy ( $\mathrm{P}=0.0117$; Fig. 3). A multivariate analysis demonstrated that age, AR expression and a strong NED were independent characteristics for prognosis following CRPC biopsy (Table VI).

\section{Discussion}

In the present study, the AR was positive for the HSPC. However, 9/28 patients (32.1\%) with CRPC were negative for the AR. Therefore, a significant number of CRPC cases did not have the AR in the primary prostate. The information for AR expression in CRPC is limited. Generally, it has 
Table III. AR expression and NED in HSPC and CRPC.

\begin{tabular}{lrrc}
\hline & $\begin{array}{r}\text { HSPC } \\
(\text { No. })\end{array}$ & $\begin{array}{r}\text { CRPC } \\
\text { (No.) }\end{array}$ & $\begin{array}{c}\text { P-value } \\
\text { (Chi-square test) }\end{array}$ \\
\hline $\begin{array}{l}\text { AR expression } \\
\text { Negative }\end{array}$ & 0 & 9 & 0.0049 \\
Positive & 20 & 19 & \\
NED & & & \\
$\quad$ Negative & 11 & 8 & 0.0649 \\
Positive & 9 & 20 & \\
\end{tabular}

$\mathrm{AR}$, androgen receptor; NED, neuroendocrine differentiation; HSPC, hormone-sensitive prostate cancer; CRPC, castration-resistant prostate cancer.

Table IV. Association between NED and androgen receptor expression in CRPC.

\begin{tabular}{lccc}
\hline & \multicolumn{2}{c}{ NED } & \\
\cline { 2 - 3 } AR expression & $\begin{array}{c}\text { Negative } \\
\text { (No.) }\end{array}$ & $\begin{array}{c}\text { Positive } \\
\text { (No.) }\end{array}$ & $\begin{array}{c}\text { P-value } \\
\text { (Chi-square test) }\end{array}$ \\
\hline Negative & 0 & 9 & 0.0292 \\
Positive & 8 & 11 & \\
\hline
\end{tabular}

$\mathrm{AR}$, androgen receptor; NED, neuroendocrine differentiation.

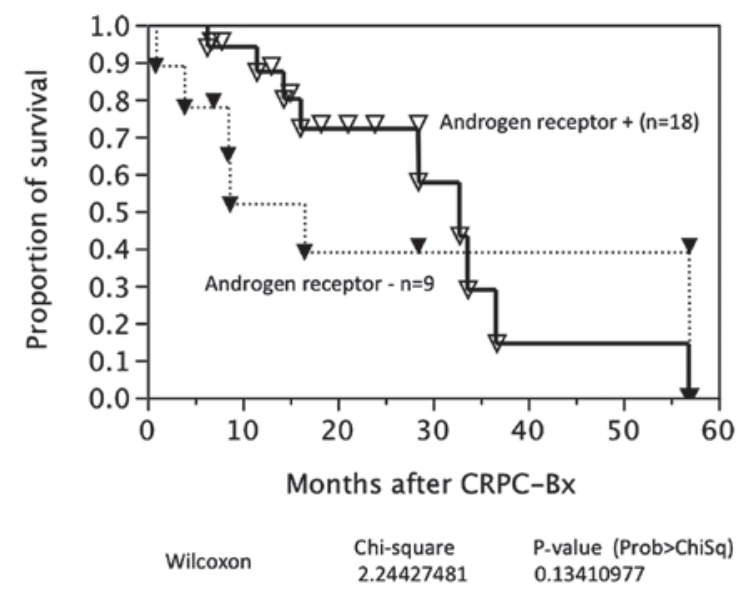

Figure 2. Cause-specific survival after castration-resistant prostate cancer (CRPC) biopsy, based on androgen receptor expression.

been reported that the AR is expressed in nearly all types of cancers of the prostate, before and after androgen ablation therapy (11). The high levels of AR expression and the development of hypersensitive receptors have been recognized as a feature associated with the development of CRPC $(13,16)$. Hobisch et al (17) showed that metastases from PCa expressed the AR following endocrine therapy. From a Rapid Autopsy Program, Shah et al (18) indicated that the majority of patients
Table V. Treatments before and after CRPC biopsy.

\begin{tabular}{lcc}
\hline Treatments & $\begin{array}{c}\text { Before CRPC biopsy } \\
\text { (No. of patients) }\end{array}$ & $\begin{array}{c}\text { After CRPC biopsy } \\
\text { (No. of patients) }\end{array}$ \\
\hline $\begin{array}{l}\text { Radiation } \\
\text { Radical } \\
\text { prostatectomy }\end{array}$ & 3 & 7 \\
$\begin{array}{l}\text { Alternative } \\
\text { anti-androgen }\end{array}$ & 13 & 0 \\
$\begin{array}{l}\text { Estramustine } \\
\text { monophosphate }\end{array}$ & 5 & 6 \\
$\begin{array}{l}\text { Cisplatin } \\
\text { Low-dose } \\
\text { prednisone }\end{array}$ & 0 & 20 \\
Low-dose & 1 & 2 \\
dexamethasone & 2 & 2 \\
$\begin{array}{l}\text { Ethinylestradiol } \\
\text { Paclitaxel }\end{array}$ & 2 & 5 \\
$\begin{array}{l}\text { Docetaxel } \\
\text { Etoposide }\end{array}$ & 0 & 0 \\
Angiotensin II & 0 & 11 \\
receptor blockers & 1 & 2 \\
\end{tabular}

CRPC, castration-resistant prostate cancer.

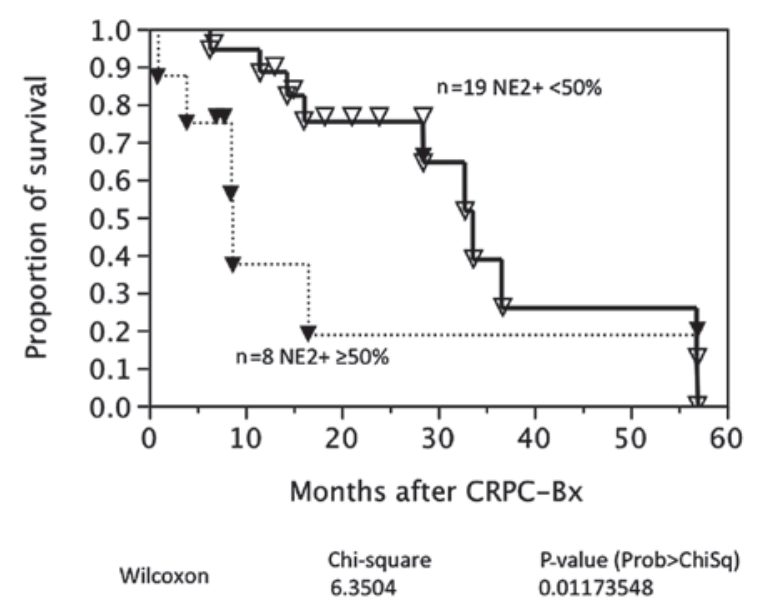

Figure 3. Cause-specific survival after castration-resistant prostate cancer (CRPC) biopsy according to neuroendocrine differentiation.

continued to express substantial quantities of AR despite having undergone a long-term androgen ablation. The patients demonstrated marked differences in AR expression between different tissue sites (2- to 50-fold) and several patients demonstrated a high amount of AR staining, although they were no longer responding to androgen-deprivation therapy. In the Japanese studies, Takeda et al (19) demonstrated that patients with metastatic PCa with $\geq 48 \%$ AR-positive cells had a significantly better outcome, in terms of progression-free and cause-specific survival compared to patients with $<48 \%$ AR content. Masai et al (20) have shown that $33 \%$ of cancer cells were positive for the AR in regrowing prostates from 8 relapsed cancers after endocrine therapy. The AR-positive 
Table VI. A multivariate analysis of the prognostic features after CRPC biopsy.

CI

\begin{tabular}{lcccc} 
Characteristics & Lower to upper limits & Chi-square & P-value (Prob > ChiSq) & Hazard ratio \\
\hline${\text { Age at CRPC } \text { biopsy }^{\mathrm{a}} \text { (years) }}$ & 0.00233 to 0.25589 & 3.99141 & $0.04573^{\mathrm{b}}$ & 1.13021 \\
iPSA $^{\mathrm{a}}$ (ng/ml) & -0.00051 to 0.00010 & 1.02092 & 0.31230 & 0.99987 \\
rPSA $^{\mathrm{a}}$ (ng/ml) & -0.02385 to 0.01026 & 0.36536 & 0.54554 & 0.99509 \\
M at CRPC biopsy +/- & -2.67880 to 0.06644 & 3.35616 & 0.06695 & 8.30273 \\
AR +/- & -2.68520 to -0.09616 & 4.59882 & $0.03199^{\mathrm{b}}$ & 12.21495 \\
Strong NED +/- & 0.42617 to 3.21225 & 7.58827 & $0.00587^{\mathrm{b}}$ & 26.75226
\end{tabular}

${ }^{a}$ Continuous; ${ }^{b}$ statistically significant.CRPC, castration-resistant prostate cancer; PSA, prostate-specific antigen; iPSA, initial PSA; rPSA, PSA at castration-resistant progression; $\mathrm{M}$, metastasis; $\mathrm{AR}$, androgen receptor; NED, neuroendocrine differentiation; CI, confidence interval.

cells were more frequently found in untreated PCa. However, the frequency of AR loss was not shown in the Japanese series. Matei et al (21) previously reported that the AR was positive in neoplastic cells in 20/47 patients (53\%) with CRPC. Therefore, $47 \%$ of CRPC cases lost AR expression, which is higher compared to our series. These results indicate that loss of the AR may be identified in a subset of CRPC and should alert physicians to the use of androgen- or AR-targeted therapies without conducting an evaluation of AR expression. It is important to analyze expression profiles prior to targeted therapies. For example, the expression of the estrogen and progesterone receptors and HER2 are frequently evaluated in breast cancer tissues to estimate the response to treatment. Trastuzumab is used for HER2+ breast cancer therapy (15).

NED was found in 9/20 HSPC (45\%) and 20/28 CRPC cases $(71 \%)$ in the present study. Its frequency was slightly higher in CRPC. Strong NED was found in 9/28 CRPC (32.1\%). NED was determined using IHS or serum NE marker concentrations (9). Using IHS, the NE cells were identified in $\sim 10-100 \%$ of the untreated PCa tissues. This large discrepancy in prevalence between studies is explained in part by the lack of quantitative and consistent tissue-imaging techniques. McWilliam et al (22) found NED in 52\% of PCa tissues using IHS for CGA and NSE. They also demonstrated a significant correlation between NED and worsening tumor differentiation, the presence of bone metastasis and poor patient survival. Kokubo et al (23) showed that $22 \%$ of stage D2 PCa overexpressed CGA by IHS and that CGA positivity was correlated with a shorter time to recurrence after hormone therapy. Kamiya et al (24) demonstrated that the cause-specific survival was significantly poorer after hormone therapy in stage D2 PCa with strongly positive staining for independent CGA and combined CGA with NSE. In the setting of CRPC, Mucci et al (25) reported that NE expression was heterogeneous and observed in 4/12 autopsy cases (33\%) when the tumor sites per case were considered among rapid autopsies from men with hormone refractory PCa. Tanaka et al (10) reported that lesions predominantly composed of a neuroendocrine cell tumor were found in 4/20 autopsy cases (20\%) of Japanese PCa patients. Therefore, our finding is consistent with findings of previous studies. However, information is limited in terms of the survival significance of NED in CRPC. Tanaka et al (10) also demonstrated that the survival was brief after relapse, although the duration of control by employing endocrine therapy varied in the neuroendocrine cell tumors found at autopsy. An evaluation of NED was performed only within the primary prostate in this study. The state of NED in metastases was unknown unlike the autopsy series. However, NED at CRPC biopsy was a strong and independent prognostic factor in the Cox proportional hazard model. NED was associated with a negative AR expression in this study, which is consistent with previous findings (9) and the significance of NED in the mechanisms of CRPC was confirmed. In addition, these results support the importance of performing a CRPC biopsy. In the present study, we found two neuroendocrine cancers by CRPC biopsy and patients underwent etoposide and cisplatin (EP) therapy $(26,27)$ instead of taxane-based chemotherapy.

There are, however, limitations to this study. The study design was retrospective. The results may be different if performed in a prospective manner. The study sample size was small; however, this number of CRPC specimens is believed to be the best in Japan. The results may have been different if the study was conducted on a larger and different population. Quantification of the staining intensity was visually performed, which is a traditional method for IHS. This may be better analyzed by multiple pathologists or by using computeraided methods to avoid inter-observer or inter-institutional variations (28). If NED was otherwise determined, the results could also have been affected. The CRPC biopsy findings were obtained only from the prostate. Therefore, the expression profiles in metastatic cites were not evaluated, unlike the autopsy series.

In conclusion, the AR was lost in a subset of CRPC, in which AR-targeted therapy might not be effective. NED was observed more frequently in CRPC vs. HSPC. NED was associated with a loss of the AR and worse prognosis in CRPC. Thus, CRPC biopsy may be useful to better characterize the diseases.

\section{References}

1. Suzuki H, Komiya A, Kamiya N, Imamoto T, Kawamura K, Miura J, Suzuki N, Nakatsu H, Hata A and Ichikawa T: Development of a nomogram to predict probability of positive initial prostate biopsy among Japanese patients. Urology 67: 131-136, 2006. 
2. Yano M, Imamoto $T$, Suzuki $H$, Fukasawa S, Kojima S, Komiya A, Naya Y and Ichikawa T: The clinical potential of pretreatment serum testosterone level to improve the efficiency of prostate cancer screening. Eur Urol 51: 375-380, 2007.

3. Scher HI, Halabi S, Tannock I, Morris M, Sternberg CN, Carducci MA, Eisenberger MA, Higano C, Bubley GJ, Dreicer R, Petrylak D, Kantoff P, Basch E, Kelly WK, Figg WD, Small EJ, Beer TM, Wilding G, Martin A, Hussain M; Prostate Cancer Clinical Trials Working Group: Design and end points of clinical trials for patients with progressive prostate cancer and castrate levels of testosterone: recommendations of the Prostate Cancer Clinical Trials Working Group. J Clin Oncol 26: 1148-1159, 2008.

4. Scher HI, Buchanan G, Gerald W, Butler LM and Tilley WD: Targeting the androgen receptor: improving outcomes for castration-resistant prostate cancer. Endocr Relat Cancer 11: 459-476, 2004.

5. Attar RM, Takimoto $\mathrm{CH}$ and Gottardis MM: Castration-resistant prostate cancer: locking-up the molecular escape routes. Clin Cancer Res 15: 3251-3255, 2009

6. De Bono JS, Logothetis CJ, Molina A, Fizazi K, North S, Chu L, Chi KN, Jones RJ, Goodman OB Jr, Saad F, Staffurth JN Mainwaring P, Harland S, Flaig TW, Hutson TE, Cheng T, Patterson H, Hainsworth JD, Ryan CJ, Sternberg CN, Ellard SL, Fléchon A, Saleh M, Scholz M, Efstathiou E, Zivi A, Bianchini D, Loriot Y, Chieffo N, Kheoh T, Haqq CM, Scher HI; COU-AA-301 Investigators: Abiraterone and increased survival in metastatic prostate cancer. N Engl J Med 364: 1995-2005, 2011.

7. Tran C, Ouk S, Clegg NJ, Chen Y, Watson PA, Arora V, Wongvipat J, Smith-Jones PM, Yoo D, Kwon A, Wasielewska T, Welsbie D, Chen CD, Higano CS, Beer TM, Hung DT, Scher HI Jung ME and Sawyers CL: Development of a second-generation antiandrogen for treatment of advanced prostate cancer. Science 324: 787-790, 2009.

8. Scher HI, Fizazi K, Saad F, Taplin ME, Sternberg CN, Miller MD, de Wit R, Mulders P, Chi KN, Shore ND, Armstrong AJ, Flaig TW, Fléchon A, Mainwaring P, Fleming M, Hainsworth JD, Hirmand M, Selby B, Seely L, de Bono JS; AFFIRM Investigators: Increased survival with enzalutamide in prostate cancer after chemotherapy. N Engl J Med 367: 1187-1197, 2012.

9. Komiya A, Suzuki H, Imamoto T, Kamiya N, Nihei N, Naya Y, Ichikawa $\mathrm{T}$ and Fuse $\mathrm{H}$ : Neuroendocrine differentiation in the progression of prostate cancer. Int J Urol 16: 37-44, 2009.

10. Tanaka M, Suzuki Y, Takaoka K, Suzuki N, Murakami S, Matsuzaki O and Shimazaki J: Progression of prostate cancer to neuroendocrine cell tumor. Int J Urol 8: 431-436, 2001.

11. Grossmann ME, Huang H and Tindall DJ: Androgen receptor signaling in androgen-refractory prostate cancer. J Natl Cancer Inst 93: 1687-1697, 2001

12. Zegarra-Moro OL, Schmidt LJ, Huang H and Tindall DJ: Disruption of androgen receptor function inhibits proliferation of androgen-refractory prostate cancer cells. Cancer Res 62 1008-1013, 2002.

13. Chen CD, Welsbie DS, Tran C, Baek SH, Chen R, Vessella R, Rosenfeld MG and Sawyers CL: Molecular determinants of resistance to antiandrogen therapy. Nat Med 10: 33-39, 2004.

14. Crook JM, O'Callaghan CJ, Duncan G, Dearnaley DP, Higano CS, Horwitz EM, Frymire E, Malone S, Chin J, Nabid A, Warde P, Corbett T, Angyalfi S, Goldenberg SL, Gospodarowicz MK, Saad F, Logue JP, Hall E, Schellhammer PF, Ding K and Klotz L: Intermittent androgen suppression for rising PSA level after radiotherapy. N Engl J Med 367: 895-903, 2012.
15. Nagata T, Shimada Y, Sekine S, Hori R, Matsui K, Okumura T, Sawada S, Fukuoka J and Tsukada K: Prognostic significance of NANOG and KLF4 for breast cancer. Breast Cancer: Apr. 17, 2012 (Epub ahead of print).

16. Bonkhoff $\mathrm{H}$ and Berges R: From pathogenesis to prevention of castration resistant prostate cancer. Prostate 70: 100-112, 2010.

17. Hobisch A, Culig Z, Radmayr C, Bartsch G, Klocker H and Hittmair A: Distant metastases from prostatic carcinoma express androgen receptor protein. Cancer Res 55: 3068-3072, 1995.

18. Shah RB, Mehra R, Chinnaiyan AM, Shen R, Ghosh D, Zhou M, Macvicar GR, Varambally S, Harwood J, Bismar TA, Kim R, Rubin MA and Pienta KJ: Androgen-independent prostate cancer is a heterogeneous group of diseases: lessons from a rapid autopsy program. Cancer Res 64: 9209-9216, 2004.

19. Takeda H, Akakura K, Masai M, Akimoto S, Yatani R and Shimazaki J: Androgen receptor content of prostate carcinoma cells estimated by immunohistochemistry is related to prognosis of patients with stage D2 prostate carcinoma. Cancer 77: 934-940, 1996.

20. Masai M, Sumiya H, Akimoto S, Yatani R, Chang CS, Liao SS and Shimazaki J: Immunohistochemical study of androgen receptor in benign hyperplastic and cancerous human prostates. Prostate 17: 293-300, 1990

21. Matei DV, Renne G, Pimentel M, Sandri MT, Zorzino L, Botteri E, De Cicco C, Musi G, Brescia A, Mazzoleni F, Tringali V, Detti S and de Cobelli O: Neuroendocrine differentiation in castration-resistant prostate cancer: a systematic diagnostic attempt. Clin Genitourin Cancer 10: 164-173, 2012.

22. McWilliam LJ, Manson C and George NJ: Neuroendocrine differentiation and prognosis in prostatic adenocarcinoma. Br J Urol 80: 287-290, 1997

23. KokuboH, Yamada Y,Nishio Y,Fukatsu H,HondaN,Nakagawa A, Saga S, Tsuzuki T and Hara K: Immunohistochemical study of chromogranin A in Stage D2 prostate cancer. Urology 66: $135-140,2005$

24. Kamiya N, Suzuki H, Kawamura K, Imamoto T, Naya Y, Tochigi N, Kakuta Y, Yamaguchi K, Ishikura H and Ichikawa T: Neuroendocrine differentiation in stage D2 prostate cancers. Int J Urol 15: 423-428, 2008

25. Mucci NR, Akdas G, Manely S and Rubin MA: Neuroendocrine expression in metastatic prostate cancer: evaluation of high throughput tissue microarrays to detect heterogeneous protein expression. Hum Pathol 31: 406-414, 2000.

26. Amato RJ, Logothetis CJ, Hallinan R, Ro JY, Sella A and Dexeus FH: Chemotherapy for small cell carcinoma of prostatic origin. J Urol 147: 935-937, 1992.

27. Komiya A, Yasuda K, Nozaki T, Fujiuchi Y, Hayashi S and Fuse H: Small cell carcinoma of the prostate after high-doserate brachytherapy for low-risk prostatic adenocarcinoma. Oncol Lett 5: 53-56, 2013.

28. Rizzardi AE, Johnson AT, Vogel RI, Pambuccian SE, Henriksen J, Skubitz AP, Metzger GJ and Schmechel SC: Quantitative comparison of immunohistochemical staining measured by digital image analysis versus pathologist visual scoring. Diagn Pathol 7: 42, 2012 